\title{
ESTETIKA DAKWAH DALAM LAGU JAWA
}

\author{
Tamyizul Ibad \\ Dosen Tetap Sekolah Tinggi Ilmu Tarbiyah (STIT) Raden Wijaya Mojokerto. \\ Email: tamyizuli@yahoo.co.id
}

\section{Abstract}

The study elaborates the arts of dakwah in the Javanese songs; Sluku-sluku Bathok and Turi-turi Putih. Both songs are one of the dakwah strategies conducted by the previous Ulemas in order that the society could accept the dakwah effectively. The use of the Javanese songs in the dakwah has become a particular characteristic of acculturation of Islam and Javanese culture. In fact, Javanese society has pleasantly accepted the Islamic dakwah.

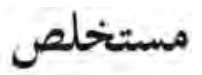

تحاول هذه المقالة استنباط آداب الدعوة الإسالامية في الأغاني الترائية الجاوية مثل سُلوك-ك


تعتبران مثالاً لإحدى استراتيجيات الدعوة اليتي كان يقوم بها الدعاة إبّان دخول الإسلام إلى جاوة الإندو ئيسية لجذب الانتباه وكسب حب الجمهور آنذاك، وهو ما نجحوا فيه بشكل كبير.

Keywords: Dakwah, Islam, Media, Lagu Jawa

\section{A. Pendahulan}

Islam adalah agama dakwah, yaitu agama yang senantiasa mengajak umatnya untuk selalu aktif melakukan kegiatan dakwah. Islam juga mengemban tugas mulai bagi pembentukan nilai humaniora (nilai-nilai kemanusiaan). Bukan sebaliknya, bertentangan dengan nilai fitrah manusia. 
Kesempurnaan Islam tercermin dan tergantung bagaimana bentuk tingkah laku, perbuatan dan penyampaian terhadap masyarakat. Suatu hal yang tidak dapat dipungkiri bahwa manusia hidup di dunia ini pasti dihadapkan dengan berbagai masalah kehidupan yang serba kompleks. Problema kehidupan itu setidak-tidaknya akan memberikan dampak tersendiri dalam jiwa manusia, salah satunya adalah kejenuhan. Maka situasi yang demikian itu kemungkinan dapat memberikan akses yang negatif terhadap perilaku manusia.

Mengatasi kompleksnya masalah pelik di dunia ini diperlukan hal-hal baru yang bisa sedikit membuat manusia itu teguh dan tabah menghadapinya. Dalam konteks demikian diperlukan dakwah yang humanis. Maksudnya, dakwah dengan memunculkan ide atau kreatifitas baru. Sebab, sulit disangkal bahwa kesuksesan dakwah itu tergantung dari cara memberikan sentuhan nilai-nilai keislaman pada ide kreatif.

Dakwah merupakan aktifitas yang sangat penting dalam Islam. Dengan dakwah Islam bisa tersebar dan diterima oleh manusia. Sebaliknya, tanpa dakwah Islam akan semakin jauh dari masyarakat, sehingga nilai-nilai Islam yang rạmat li al-âlamîn tak tersalurkan. Bahwa prinsip dakwah Islam adalah amar makruf nabi munkar (berbuat kebaikan dan mencegah kemungkaran). Ini berarti mengembangkan kewajiban ibadah manusia sebagi khalifah bagi kemakmuran kehidupan duniawi.

Al-Qur'an menjelaskan cara berdakwah, seperti hikmah, nasihat yang benar dan mujâdalah atau diskusi (berbantah dengan cara yang paling baik. Hal ini diserukan dalam firman Allah Surat an-Nahl ayat 125: Serulah (manusia) kepada jalan Tuhanmu dengan hikmah dan pelajaran yang baik dan bantablah mereka dengan cara yang baik. Sesunggubnya Tuhanmu Dialah yang lebih mengetahui tentang siapa yang tersesat dari jalan-Nya dan Dialah yang lebih mengetahui orangorang yang mendapat petunjuk. ${ }^{1}$

Selain firman tersebut, metode dakwah juga diserukan oleh Nabi Muhammad sebagaimana diriwayatkan Imam Turmuzi: Barangsiapa melihat kemunkaran, hendaklah mengubab dengan tangan, jika tak mampu dengan lidah, dan jika masih tak mampu maka dengan hati. Hal ini adalab selemahlemabnya iman. ${ }^{2}$

1 Departeman Agama Republik Indonesia, Al-Qur'an Dan Terjemahnya, (Jakarta: CV. Toha Putra, 1989), hal. 421.

2 Sunan Turmudzi, al-Jâmi'u Shậh $\underline{\underline{h}}$ Juz IV, (Beirut Libanon: Darul Kitab Al-Alamiyah, tt) hal. 408. 


\section{B. Konsepsi Dakwah}

Dari sumber metode itu tumbuh metode-metode yang merupakan operasionalisinya, yaitu dakwah dengan lisan, tulisan, seni, dan dengan teladan atau perbuatan (bi al-bâad). Dakwah dengan lisan berupa ceramah, seminar, simposium, diskusi, khutbah, sarasehan, dan lain-lain. Dakwah dengan tulisan berupa buku, majalah, surat kabar, sepanduk, pamflet, lukisan-lukisan dan lain-lain. Dakwah bi al-bâl berupa perilaku yang sopan sesuai dengan ajaran al-Islam, memelihara lingkungan, mencari nafkah dengan tekun, ulet, sabar, semangat, kerja keras, menolong sesama manusia, semua meliputi beberapa sektor. Itu semua bisa terwujud dengan usaha dan juga meliputi sektor kehidupan sekarang. Metode seni meliputi seni lukis, seni tari, seni suara, atau musik, drama, sinetron, film, dan sebagainya. Seni juga bisa membuat opini masyarakat tentang sesuatu yang diperankannya. Seni juga bisa membangun sesuatu perasaan keagamaan atau menggantikan perasaan yang telah melekat dengan perasaan yang baru. ${ }^{3}$

Selain cara atau metode dakwah juga harus mempunyai media dakwah. Yang dimaksud media dakwah adalah peralatan yang dipergunakan untuk dakwah. Dan pada zaman modern ini manusia sangat jeli dalam memilih alat atau media untuk memberikan materi dakwah di dalamnya: seperti televisi, vidio, kaset rekaman, majalah, surat kabar, dan seperti yang tersebut di atas, termasuk melalui berbagai macam upaya dalam sektor kehidupan. ${ }^{4}$

Dengan media seperti itu, diperlukan kreatifitasnya seorang dai dalam memasukkan nilai-nilai dakwah. Sehingga dapat diserap dengan mudah oleh sang pelihat media. Selain itu seorang dai juga di tuntut untuk kaya alternatif dalam menyebarkan ajaran-ajaran Islam, untuk dapat memberikan nilai-nilai dakwah yang sekiranya mudah diserap oleh masyarakat.

Kemampuan dai yang berbeda-beda memungkinkan penggunaan media yang berbeda-beda pula. ${ }^{5}$ Jenis bakat yang menjadi hobinya seperti suara bagus, bakat menulis syair baik puisi bisa dikembangkan dengan mengarah pada tidak hanya sebagai hiburan dan bakat saja melainkan memanfaatkan bakatnya sebagai media penempatan nilai-nilai dakwah. Apalagi media elektronik sekarang sangat digemari oleh seluruh lapisan masyarakat. Salah satu kaset rekaman yang mudah didapatkan

3 Wardi Bahtiar, Metodologi Penelitian Ilmu Dakwah, cet. I, (Jakarta : Logos, 1997), hal. 40.

4 Ibid., hal. 35.

5 Ibid., hal. 41. 
masyarakat dari berbagai lapisan. Salah satu contoh fenomena sosial yang terjadi saat ini adalah mengemas suatu karya tulis (baik syair puisi atau bahkan berpidato) pun menggunakan kaset. Dari situ kreatifitas seorang da'i diperlukan dalam menyampaikan tugas dakwahnya sebagai umat Islam. Masyarakat dalam memilih sebuah kaset itu di sesuaikan dengan apa yang digemari.

Contoh adalah lagu Jawa Sluku-sluku Bathok dan Turi-turi Putih. Kedua lagu ini kerap diputar. Meski terkesan santai dan enak didengar telinga, namun sesungguhnya ada unsur dakwah yang terkandung di dalamnya. Untuk lebih detailnya kedua lagu Jawa tersebut adalah sebagai berikut:

\section{Sluku-sluku Bathok}

Sluku-sluku batok

Bato'e ela-elo

Si romo menyang solo

Leb olebe paying muto

Mak jentit lolo lobah

Wong mati ora obah

Yen obah medeni bocah

Yen urib ibadah sing tertib

Sinten tiyang lintang dalan

Krono ngaji ilmu pengeran

Gusti Alloh nggampangno dalan

Dating suargo sarono aman

Durrotun nasibin ngeb wonten cerito

Ngeh wontenmayit mayet kalungan ulo

Sebab salahe ora keroso

Mayite salab telung perkoro

Kerungu azan gak gelem teko

Sholat jama'ah rodo kepekso

Sangking repote ngurusi dunyo

Shalat jama'ah gak digatekno.......

\section{Turi-turi Putih}

Turi-turi putih di tandur neng kebun agung

Turi-turi putib di tandur neng kebun agung 
Cleret tibo nyemplung, bhok iro kembange opo

Mbok iro ......mbok iro.......mbok iro kembange opo

Kembang-kembang melati

Kembang melati wangi ambune

Ayo seneng melu ngaji

Supoyo slamet dunyo akbirate

Mbok iro ......mbok iro.......mbok iro kembange opo

Kembang-kembang tomat

Kembange tomat sak arat-arat

Ayo bareng moco sholawat,

Supoyo slamet dunyo akbirat

Mbok iro ......mbok iro......mbok iro kembange opo

Tekane akbir zaman

Srengengene ora metu songko wetan

Akeh wong dob nagku iman

Nangeng ora nglakoni perintabe pengeran

Mbok iro ......mbok iro......mbok iro kembange opo

\section{Tabel Nilai Dakwah}

\begin{tabular}{|c|c|c|c|}
\hline No & Judul Lagu & Bait Lagu & Nilai Dakwah \\
\hline \multirow[t]{3}{*}{1} & \multirow[t]{3}{*}{$\begin{array}{l}\text { Sluku-sluku } \\
\text { Bathok }\end{array}$} & $\begin{array}{l}\text { Mak jentit lolo lobah } \\
\text { Wong mati ora obah } \\
\text { Yen obah medeni bocah } \\
\text { Yen urip ibadah sing tertib }\end{array}$ & Kehidupan \\
\hline & & $\begin{array}{l}\text { Sinten tiang lintang dalan } \\
\text { Krono ngaji ilmu pangeran } \\
\text { Gusti Allah gampangno dalan } \\
\text { Dating suargo sarono amal } \\
\end{array}$ & Ilmu Pengetahuan \\
\hline & & $\begin{array}{l}\text { Duratun nasikhin Ngah wonten cerito } \\
\text { Ngeh wonten mayit kalungan ulo } \\
\text { Sebab salahe ora kroso } \\
\text { Mayite salah telung perkoro } \\
\text { Kerungu adzan gak gelem teko } \\
\text { Sholat jama'ah rodo kepekso } \\
\text { Saking repote ngurusi dunyo } \\
\text { Sholat jama'ah gak di gatekno }\end{array}$ & Kehidupan \\
\hline \multirow[t]{2}{*}{2.} & \multirow[t]{2}{*}{ Turi-turi Putih } & $\begin{array}{l}\text { Ayo seneng melu ngaji } \\
\text { Supoyo slamet dunyo akhirate } \\
\text { Ayo bareng moco shalawat } \\
\text { Supoyo selamet dunyo akhirat }\end{array}$ & Akidah \\
\hline & & $\begin{array}{l}\text { Tekane akhir zaman } \\
\text { Srengenge ora metu songko wetan } \\
\text { Akeh wong do ngaku iman } \\
\text { Nanging ora nglakoni perintahe pengeran }\end{array}$ & Kehidupan \\
\hline
\end{tabular}




\section{Analisis Data}

Dari diskripsi data yang sudah ada maka perlu kiranya untuk mengenali isi lagu Jawa sesuai dengan bentuk kesan materi dakwah dalam pedoman ajaran Islam, yaitu al-Qur'an dan hadits karena pada intinya materi dakwah keseluruhan itu berpangkal dari al-Qur'an dan hadits.

\section{Sluku-sluku Bathok}

Lagu Sluku-sluku Bathok pada mulanya bait syairnya adalah:

Sluku-sluku bathok

Bathoe ela-elo

Siromo menyang solo olebe payung muto

Lagu ini berasal dari bahasa Jawa yang asli yang kerap dibuat permainan oleh anak-anak kecil di zaman dahulu. ${ }^{6}$ Tetapi sebenarnya merupakan cerita yang patut dijadikan suri tauladan bagi umat manusia, sehingga bait selanjutnya adalah:

Mak jentit lolo lobah

Wong mati ora obah

Yen obah medeni bocah

Yen urip ibadah sing tertib

Maksudnya, bahwa suatu saat itu orang akan mati maka dari itu sewaktu masih di beri kesempatan hidup seharusnya digunakan untuk beribadah dengan sungguhsungguh. Bait ini masuk pada kategori pesan dakwah dengan masalah kehidupan, dakwah memperkenalkan dua jenis kehidupan, yaitu kehidupan bumi yang sangat terbatas ruang dan waktunya (al-Hayatuddunya) dan kehidupan akhirat yang tak terbatas dan kekal abadi sifatnya. ${ }^{7}$

Keterbatasan kehidupan di dunia ditandai dengan kematian yang datangnya tidak bisa ndi duga-duga oleh akal dan pikiran manusia karena hal itu sudah merupakan takdir atau ketentuan dari Allah, juga karena kematian itu tidak terduga datangnya tiba-tiba maka dari itu oleh Allah diberi kesempatan untuk hidup dan seyogyanya manusia itu memanfaatkan waktu dengan beribadah. Hal ini dimaksudkan sebagai bekal di kehidupan akhirat. Kejelasan ini sudah termuat dalam firman Allah surat Ali Imron ayat 185 yakni:

6 Hasil wawancara dengan Bapak Prapto, pada 20 April 2002.

7 Muhammad Ali Aziz, Imu Dakwah, (Surabaya: Fakultas Dakwah IAIN Sunan Ampel, 1993), hal. 62. 
Tiap-tiap yang berjiwa akan merasakan mati. Dan sesunggubnya pada hari kiamat sajalah disempurnakan pahalamu. Barangsiapa dijaubkan dari neraka dan dimasukean ke dalam surga, maka sungguh ia telah beruntung. Kebidupan dunia itu tidak lain hanyalah kesenangan yang memperdayakan. (Q.S. Ali Imron: 185). ${ }^{8}$

Ayat ini telah menjelaskan dan telah menuntun bagi umat manusia serta memberikan petunjuk bahwa telah mati manusia sudah tidak bisa beramal ibadah lagi. Maka dari itu kesempatan eramal ibadah hanya satu kali yaitu seaktu masih hidup. Berbicara mengenai "waktu" mengingatkan penulis pada ungkapan malik bin Nabi dalam bukunya syuruth an-nahdhah (syarat-syarat kebangkitan).

Waktu adalah sungai yang mengalir keseluruh penjuru sejak dulu kala melintasi pulau, kota, dan desa, membangkitkan semangat atau menina bobokan manusia. Ia diam seribu bahasa, sampai-sampai manusia sering tidak menyadari kehadiran waktu dan melupakan nilainya, walupun segala sesuatu (selain Tuhan) tidak akan mampu melepaskan diri darinya. ${ }^{9}$

Waktu yang terlewati sudah tidak bisa terulang kembali, kita sebagai manusia yang diciptakan olah Allah paling sempurna tetapi hal itu tidak menjamin kepandaian yang sempurna tidak ada satupun mahluk Allah yang bisa memutar waktu. Oleh karena itu menyia-nyiakan waktu adalah hal yang paling bodoh untuk dilakukan. Kecuali menggunakan waktu itu dengan hal-hal yang bermanfaat sehingga bisa menguntungkan kehidupan baik di dunia maupun di akhirat.

Pembahasan pada selanjutnya yaitu bait syair lagu Jawa yang berbunyi:

Sinten tiang lintang dalan

Kerono ngaji ilmu pangeran

Gusti Allah gampangno dalan

Dateng suargo sarono amal

Maksudnya, bahwa siapa orang berjalan karena menuntut ilmu Allah maka Allah akan mempermudah jalan kesurga dengan aman. Jika orang itu berilmu maka dalam segala tindakan dan perbuatan itu akan dipikirkan sesuai dengan ilmu yang telah di dapat. Orang yang berilmu tentunya dapat membedakan mana yang benar dan mana yang salah.

8 Departemen Agama RI, Al-Qur'an Dan Terjemahannya..., hal. 45.

9 Qurais Syihab, Wawasan al-Qur'an, Cet. I (Bandung, Penerbit Mizan, 1998), hal. 45. 
Penjelasasn bait syair lagu jawa ini meyangkut tentang ilmu-ilmu Allah menyangkup seluruh isi alam ini, kedudukan ilmu sangat penting dalam kehidupan menurut al-Qur'an manusia adalah makhluk yang berpotensi untuk mengetahui ilmu pengetahuan. Allah lah yang megajarkan semua hal yang sebelumnya tidak diketahunya. ${ }^{10}$ Sedangkan hakekat pencarian ilmu pengetahuan pada diri manusia sesungguhnya adalah dalam rangka mengenal Allah SWT dengan segala konsekuensinya (Tauhidullah) ini merupakan tujuan pertama dan utama. Patut di ingat, ayat al-Qur'an yang pertama kedalam hati Rasulullah saw pada keuatamaan ilmu pengetahuan yaitu dengan memerintahkan membaca sebagai kunci ilmu pengetahuan dan menyebut Qalam, alat transformasi ilmu pengetahuan. Allah berfirman surat al-Alaq ayat 1-5:

Bacalah dengan (menyebut) nama Tubanmu Yang menciptakan, Dia telah menciptakan manusia dari segumpal darah. Bacalah, dan Tubanmulah Yang Maha Pemurah, Yang mengajar (manusia) dengan perantaraan kalam. Dia mengajarkan kepada manusia apa yang tidak diketabuinya. (QS. Al-Alaq: 1-5) ${ }^{11}$

Surat yang pertama kali Allah turunkan kedalam al-Qur'an adalah surat alAlaq. Di dalamnya Allah SWT menyebutkan nikmatnya didalam mengajarkan manusia apa yang ia tidak ketahui. Hal itu menunjukkan akan kemulyaan belajar dan ilmu pengetahuan. ${ }^{12}$ Dengan banyak belajar dan mengamalkan ilmunya maka semakin banyak pula yang akan kita ketahui tentunya ilmu di sini bertujuan agar manusia bertaqwa dengan bukti ilmu-ilmu yang mereka terima. Dalam surat alBaqarah ayat 282 disebutkan:

...Dan bertaqwawlah kepada Allah: Allah mengajarmu dan Allah maha mengetahui segala sesuatu (QS. Al-Baqarah 282). ${ }^{13}$

Bait-bait syair berikut ini termasuk kategori pesan materi dakwah berhubungan dengan masalah kehidupan yakni:

Duratun nasikbin Ngah wonten cerito

Ngeh wonten mayit kalungan ulo

Sebab salahe ora kroso

Mayite salah telung perkoro

10 Didin Hafidhuddin, Dakwah Aktual, (Jakarta, Gema Insani, 1998), hal. 27-29.

11 Departemen Agama RI, Al-Qur'an Dan Terjemahannya..., hal. 1079.

12 Yusuf Qardawi, Al-Qur'an Bicara Tentang Akal Dan Ilmu Pengetabuan, (Jakarta: Gema Insani 1998), hal. 91

13 Departemen Agama RI, Al-Qur'an Dan Terjemahannya..., hal. 70. 
Kerungu adzan gak gelem teko

Sholat jama'ah rodo kepekso

Saking repote ngurusi dunyo

Sholat jama'ah gak di gatekno

Bait-bait ini bercerita tentang isi kitab Dzurratun Nashikhin yang di sana di jelaskan bahwa di kehidupan selanjutnya setelah mati ada orang dengan memakai kalung yang terbuat dari ular ini disebabkan karena ia tidak waspada dengan kesalahan-kesalahan yang telah dilakukan. Ada tiga kesalahan yang dilakukan oleh sang mayit:

1. Bila mendengar suara adzan dia tidak bergegas (perintah shalat)

2. Bila berjama'ah shalat karena terpaksa (tidak dengan niat yang ikhlas)

3. Tidak memperhatikan shalat jama'ahnya karena dia sibuk dengan urusan duniawinya.

Syair lagu jawa ini mempunyai maksud memperingatkan kepada manusia dengan jalan bercerita tentang salah satu siksa kubur yang diakibatkan oleh kesalahan-kesalahan mayit itu sendiri dan mengingatkan akan kewajiban beribadah adalah yang utama dalam kehidupan.

Allah berfirman dalam surat Adz-Dzariyat ayat 56:

Dan Aku tidak menciptakan jin dan manusia melainkan supaya mereka menyembah-Ku. (QS. Adz-Dzariyat: 56) ${ }^{14}$

Bahwa pada hakikatnya manusia di ciptakan oleh Allah tidak lain hanya untuk supaya mereka beribadah kepada-Nya. Karena itu jika tidak maka adzab Allah sudah menanti.

Allah juga berfirman dalam al-Qur'an Surat Thoha ayat 132 :

Dan perintabkanlah kepada keluargamu mendirikan shalat dan bersabarlah kamu dalam mengerjakannya. Kami tidak meminta rezki kepadamu, Kamilab yang memberi reqki kepadamu. Dan akibat (yang baik) itu adalab bagi orang yang bertakwa. (Q.S. Thaahaa: 132) ${ }^{15}$

Ayat ini menerangkan perihal diperintahkannyauntuk mendirikan shalat. Kewajiban shalat merupakan rukun Islam yang kedua dari kelima rukun Islam, yaitu syahadat, shalat, puasa, zakat, dan haji. Shalat juga termasuk pencegahan terhadap perbuatan munkar Allah berfirman dalam al-Qur'an surat al-Ankabut ayat 45:

14 Departemen Agama RI, Al-Qur'an Dan Terjemahannya..., hal. 862.

15 Ibid., hal. 492. 
Bacalah apa yang telah diwabyukan kepadamu, yaitu Al Kitab (Al Qur'an) dan dirikanlah shalat. Sesunggubnya shalat itu mencegah dari (perbuatanperbuatan) keji dan mungkar. Dan sesunggubnya mengingat Allab (shalat) adalah lebih besar (keutamaannya dari ibadat-ibadat yang lain). Dan Allab mengetabui apa yang kamu kerjakan. (Q.S. Al-Ankabut: 45) ${ }^{16}$

Banyak sekali ayat-ayat al-Qur'an yang menjelaskan tentang shalat karena ibadah shalat termasuk mengingat Allah, menjalin hunbungan dengan-Nya Sang Kholoq. Perlu kita ketahui didalam kehidupan kita ada dua hubungan yang harus dijalin dengan baik yaitu: hubungan dengan sang Kholiq (Allah SWT) dan hubungan dengan manusia.

Dari cerita (kisah) di atas bisa kita jadikan contoh atau sebagai suritauladan untuk menginstropeksi diri, kenyataan sekarangpun banyak hal serupa yang terjadi banyak mushollah-mushollaha dan msajid-masjid yang bila sudah waktunya shalat hanya sedikit yang datang, dikarenakan banyak yang sibuk dengan masalah-masalah pekerjaan dan kesibukan-kesibukan dunia sehingga orang lebih mudah mengesampingkan kewajiban beribadahnya.

\section{Turi-Turi Putih}

Kemasan lagu ini dibuat dengan model pantun bersajak dan pada asal mulanya lagu ini berbunyi:

Turi-turi putib ditandur ning kebun agung

Turi-turi putih ditandur ning kebun agung

Cleret tibo nyemplong mbok iro kembange opo

Mbok iro ........ Mbok iro ........ Mbok iro kembange opo

Menurut Gus Khoirul Anwar makna filosofi dari bait ini yaitu bahwa manusia pada akhirnya akan di kebumikan kedalam tanah dengan hanya memakai kain kafan oleh karena itu tuidak ada satu pun yang patut di sonmbongkan. ${ }^{17}$ Dan pada bait-bait selanjutnya dengan ditambah muatan keislaman seperti pada bait berikut:

Ayo sergep melu ngaji

Supoyo slamet dunyo akbirate

Yang artinya mari aktif ikut mengaji agar selamat dunia dan akhirat.

16 Ibid., hal. 635.

17 Kaset Rekaman Jaman Watu Kambang Nada Dan Dakwah, Zeris Production, (Ceramah Gus Khoirul Anwar. 
Maksudnya, mengajak kepada seluruh manusia untuk mencari ilmu, dengan jalan membaca seperti dimaksud dalam ayat al-Qur'an yang pertama kali turun, yaityu surat al-Alaq. Tentunya disertai dengan niat yang ikhlas karena hal ini sudah merupakan perintah Allah, orang berilmu adalah orang yang takut kepada Allah. ${ }^{18}$ Dan mereka telah di janjikan oleh Allah mendapatkan ganjaran seperti yang termuat dalam surat al-Bayyinah ayat 8:

Balasan mereka di sisi Tuhan mereka ialah surga 'Adn yang mengalir di bawahnya sungai-sungai; mereka kekal di dalamnya selama-lamanya. Allah ridha terhadap mereka dan merekapun ridha kepadaNya. Yang demikian itu adalah (balasan) bagi orang yang takut kepada Tubannya. (Q.S. al-Bayyinah:8) ${ }^{19}$

Sedangkan mengaji di sini mempunyai dua makna yaitu mencari ilmu atau membaca kitab dan kedua makna inipun saling terakit. Dalam bahasa jawa ngaji berarti mambaca al-Qur'an. Membacapun oleh Allah telah dianjurkan dalam surat al-ankabut ayat 45:

Bacalah apa yang telah diwahyukan kepadamu, yaitu al-kitab (al-Qur'an) (QS. Al-Ankabut ${ }^{20}$

Atau pada Surat Al-Alaq ayat 1:

Bacalah dengan (menyebut) nama Tuhanmu Yang menciptakan, Dia telah menciptakan manusia dari segumpal darah. Bacalah, dan Tubanmulab Yang Maha Pemurah, Yang mengajar (manusia) dengan perantaraan kalam. Dia mengajarkan kepada manusia apa yang tidak diketabuinya. (QS. Al-Alaq: 1-5) $)^{21}$

Diwahyukan oleh Allah pada Rasul untuk kita umat muslim bahwa ilmu Allah itu sangat luas maka kewajiban menuntut ilmu itu tidak ada akhirnya selama kita masih hidup, tentunya hanya karena Allah semata dan hanya bertujuan meningkatkan keimanan, ketaqwaan serta rasa syukur kita terhadap Allah SWT. Allah berfirman dalam surat al-Hujurat ayat 1:

Hai orang-orang yang beriman, janganlah kamu mendabului Allah dan RasulNya dan bertakwalah kepada Allah. Sesunggubnya Allah Maba Mendengar lagi Maha Mengetahui”. (Q.S. Al-Hujurat:1) ${ }^{22}$

18 Yusuf Qardawi, al-Qur'an dan Ilmu Pengetabuan..., hal. 93.

19 Departemen Agama RI, Al-Qur'an Dan Terjemahannya..., hal. 1085.

20 Ibid., hal. 635.

21 Ibid., hal. 1079.

22 Ibid., hal. 635. 
Dengan ayat di atas maka jelas di terangkan bahwa ketaqwaan itu sudah hal yang wajib bagi kita selaku hamba Allah SWT bahkan sudah merupakan perintah bagi semua. Dan dalam bait selanjutnya yaitu:

Ayo bareng moco shalawat

Supoyo slamet dunia akbirat

Syair ini mempunyai maksud, mengajak bersama-sama membaca shalwat untuk Nabi agar mencapai tujuan keselamatan dunia akhirat.

Rasulullah saw bersabda: Pada setiap ibadah, seruannya langsung di tujukan oleh alah kepada hambanya, tetapi ada kelainan (keistimewaan) khusus bagi (ibadah) shalawat, bahkan dinyatakan: "Allah sendirilah yang mengawalinya (bershalawat), lalu di ikuti oleh para malaikat-Nya, pada akhirnya di serukan dengan tekanan wajib bershalawat bagi manusia yang beriman (mu'min dan muslim)". Maka dengan demikian terbukti dengan nyata bahwa shalawat adalah ibadah yang paling istimewa (tertingggi) diantara ibadah-ibadah lainnya."23 Allah menjelaskan dalam al-Qur'an Surat al-Ahzab ayat 56:

Sesungguhnya Allah dan malaikat-malaikat-Nya bershalawat untuk Nabi. Hai orang-orang yang beriman, bershalawatlah kamu untuk Nabi dan ucapkanlah salam penghormatan kepadanya. (Q.S. al-Ahzab: 56) ${ }^{24}$

Dalam ayat ini menjelaskan Allah dan malaikat-Nya bershalawat untuk Nabi Muhammad saw. nah apa lagi kita sebagai hamba Allah dan sebagai umat Nabi Muhammad Allah menganjurkan kepada kita orang-orang beriman untuk bershalawat.

Berbicara "shalawat" mengandung arti yang dijelaskan dalam keterangan alQur'an terjemah yaitu kalau dari Allah berarti memberi rahmat: dari malaikat berarti memintakan ampunan dan kalau dari orang-orang mukmin berarti berdoa supaya diberi rahmat seperti dengan perkataan: "Allahumma solli ala Muhammad"25 Maka dari itu shalawat merupakan salah satu jalan untuk selamat baik di dunia maupun di akhirat.

Kemudian, pada bait selanjutnya yang berbunyi:

23 Abdul Imam Taqyuddin, Tanbihul Ghafilin Pembangun Jiwa Moral Umat, (Malang: Darul Ihya' Indonesia, 1986), hal. 405

24 Departemen Agama RI, Al-Qur'an Dan Terjemahannya..., hal. 678.

25 Ibid. 


\section{Tekane akbir Zaman}

Srengenge ora metu soko wetan

Akeb wong do ngaku iman,

Nanging ora ngelakoni perintabe pengeran

Maksudnya, bahwa datangnya hari akhir zaman (hari Qiamat) itu di tandai dengan mata hari yang tidak keluar dari timur lagi, dan banyak orang yang mengaku iman atau Islam tapi tidak menjalankan perintah Allah SWT. Jelas sekali maksud dari bait terakhir syair lagu jawa ini yaitu tentang tanda-tanda hari Qiamat. Sampaisampai Allah juga telah menjelaskan kilas tentang hari kiamat di dalam al-Qur'an yaitu pada keseluruhan surat al-Qiyamah.

Yang dijelaskan pada syair lagu jawa ini adalah sebagian tentang tanda-tanda hari kiamat yang sekarang ini hampir seluruh tanda-tanda hari kiyamat sudah ada di muka bumi kecuali hal-hal yang sangat "Besar" seperti pada bait sair lagu ini yang menjelaskan tentang keluarnya matahari tidak lagi dari timur melainkan dari barat. Dan banyak orang mengaku dirinya Islam dan iman tapi ajaran syari'at serta perinta Allah tidak dilaksanakan seperti yang terjadi di negara Indonesia kerap dijuluki dengan sebutan Islam KTP.

Dalam al-Qur'an surat al-Qiyamah juga dijelaskan tentang tanda-tanda hari qiyamat yang antara lain ayat 1-11 yang berbunyi:

Aku bersumpah dengan hari kiamat, dan aku bersumpah dengan jiwa yang amat menyesali (dirinya sendiri). Apakah manusia mengira, bahwa kami tidak akan mengumpulkan (kembali) tulang belulangnya? Bukan demikian, sebenarnya Kami kuasa menyusun (kembali) jari jemarinya dengan sempurna. Babkan manusia itu bendak membuat maksiat terus menerus. Ia bertanya: "Bilakah hari kiamat itu?" Maka apabila mata terbelalak (ketakutan), dan apabila bulan telah hilang cahayanya, dan matahari dan bulan dikumpulkan, pada hari itu manusia berkata: "Ke mana tempat lari? Sekali-kali tidak! Tidak ada tempat berlindung! (Q.S. Al-Qiyamah: 1-11) ${ }^{26}$

Pada ayat kedelapan di atas menjelaskan bahwa bulan yang tidak lagi bersinar karena bulan tidak mendapat pantulan dari matahari ini disenbabkan matahari sudah berbalik arah yaitu sudah dijelaskan pada ayat ke-9 banyak sekali orang-orang bertanya kemana tempat lari, sekali tidak! Ada tempat berlindung kecuali hanya pada tuhanmulah pada hari itu tempatmu kembali.

26 Ibid., hal. 907. 


\section{DAFTAR PUSTAKA}

Aziz, Muhammad Ali. 1993. Ilmu Dakwah. Surabaya: Fakultas Dakwah IAIN Sunan Ampel.

Bahtiar, Wardi. 1997. Metodologi Penelitian Ilmu Dakwah, cet. I. Jakarta: Logos.

Departeman Agama Republik Indonesia. 1989. Al-Qur'an Dan Terjemahnya. Jakarta: CV. Toha Putra.

Hafidhuddin, Didin. 1998. Dakwah Aktual. Jakarta, Gema Insani.

Kaset Rekaman Jaman Watu Kambang Nada Dan Dakwah, Zeris Production, (Ceramah Gus Khoirul Anwar.

Qardawi, Yusuf. 1998. Al-Qur'an Bicara Tentang Akal Dan Ilmu Pengetabuan. Jakarta: Gema Insani.

Syihab, Qurais. 1998. Wawasan al-Qur'an, Cet. I. Bandung, Penerbit Mizan.

Taqyuddin, Abdul Imam. 1986. Tanbibul Ghafilin Pembangun Jiwa Moral Umat. Malang: Darul Ihya' Indonesia.

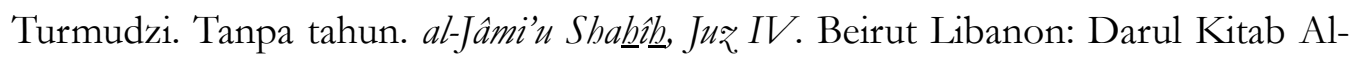
Alamiyah.

Wawancara dengan Bapak Prapto, pada 20 April 2002. 